\title{
Effect of Parenting Style on Child Behavior: A Qualitative Analysis
}

\author{
Rashid Zaman ${ }^{1}$ (corresponding author) \\ MPhil (Management Sciences) \\ Bahria University Islamabad, Pakistan ,PO box 44000, E-8, Islamabad, Pakistan \\ Email: rashidzamantanoli@gmail.com \\ Muhammad Arslan ${ }^{2}$ \\ Visiting Lecturer (SZABIST) \& Department Coordinator (SEECS, NUST) \\ MPhil (MS), Islamabad, Pakistan \\ Email: Muhammadarslan73@gmail.com \\ Dr Rashida Khatoon Malik ${ }^{3}$ \\ Head of Campus \\ SZABIST, Islamabad,PO box 44000, H-8/4, Islamabad, Pakistan \\ Asif Mehmood ${ }^{4}$ \\ MBA (Human Resource Management) \\ AIlama Iqbal Open University, Islamabad,PO box 44000, H-8/4, Islamabad, Pakistan
}

\begin{abstract}
Parting styles and its impact of child behavior is core phenomena of behavioral science that needs specific attention from researcher and practitioner around the globe. The purpose of present qualitative study is to explore the new trend of parenting style emerging in the society and their impact on child behaviors by using unstructured interviews trough homogeneous sampling of parents located in Islamabad and native areas. The data gathered from unstructured interviews was transcribed and processed through thematic analysis using NVivo 10 software. The findings of study reveal the notion that ultimately behavior of child depends upon parenting style and many factors contribute in shaping parenting style that may be external environment, support, love, affection and opportunities. Effective communication is the ultimately outcome that is effective among majority of parents and that can be used by parents in accessing their child behavior and adjusting their parenting strategies
\end{abstract}

Keywords: Communication, Support, Affection, Authoritative,

\section{INTRODUCTION}

Authorities on the child behavior development generally accepted the assumption that parents, as primary caregivers exert the original perhaps the more significance influence on the development of the child (Pretorius, 2000). A child development is therefore strongly influence by the parenting style, his environment and culture in which they grow (Louw, 2004). Therefore relationship between parent and children is utmost important. The nature of interaction, discipline and dealing with the child behavior and emotions has explicit impact on child development. The example set by parents is extremely important as a basis for interpersonal relation and social behavior. There is a growing concern about the child behavior in the society; the parents play a significant role in shaping the behavior of the children. Not all parenting styles are alike. What individual do as parents depends, somewhat on how they were brought up as child? What they observe in other family and what they have been taught. Parenting is never easy as the child whole behavior depends on which ground the child was brought up? There is insidious assumption that accurate and apt expectation for children behavior is one of the foremost factors, which contributes to parent's ability to stern young children well. Now a day's support, monitoring and discipline are central dimensions of parental behavior that are linked with child behavior and child development. Parents competency is multidimensional construct with diverse behavior (Brink, 2006), affective (Barbara, 2004), and cognitive (Coleman \& Karraker, 2000) components' personal central cognitive element of parenting competence is parenting self efficacy, which may be defined as parents self-referent estimations of competence in the parental role or as parents perception of their ability to positively influence the behavior and development of their children. In general it's the parent's ability to cope with the child developments needs and take necessary action to monitor and control the child activities and influence on his behavior .Now a days in Pakistani society depression among community is increasing because of socio and economic crises. These characteristics indulged on each and every aspect of living norms and culture. The behavioral paradigm has been affected with these issues including the parenting styles and there is a specific transformation of parenting style. The technological advancement is also leading the behavioral aspect of country. The parents now a day's use the support and 
affection strategy on the developing the child. Monitoring involves supervising children activities, keeping track of children's activities and their peer relation and requires conformity to family and community norms. When children misbehave, some parents turn to use coercive form of discipline where as some parents rely on non coercive methods such as they discussed the consequences of their behavior and make negotiation with them so that they can understand the myth behind the panorama furthermore make correction of their behavior. A large body of research indices that the optimum behavior of the children depend upon the parenting style (Barbara, 2004) and (Brink , 2006). Numerous research has documented the inter-generational continuity of parenting indicative of that present day parent tend to use similar parenting strategies or practices that they themselves received in their child hood (Bifulco, et al., 2002).Children behavior are action in response to many internal and external influences (Osborne \& Fincham, 1996). Possible internal influences of behavior are genes; metabolism, age and gender while external influences of behavior are parental behavior and peer models (Hops, Davis, Leve, \& Sheebe, 2003). Income of parents also play significant role in behavior of parents (Arslan \& Zaman, 2014). Many factors therefore tend to influence development the temperament and ability of the children, the care they receive from their parents and concerned others, the environment on which they grow up, the opportunities provided, the support available when in need or distress and role models who represent values and goals they can identity withy. Parent plays a vitally important role in most of these aspects (Morawska,Winter, \& Sanders, 2009). The researchers also argued that pre-announced product characteristics have effect on customer purchase intention (Zaman \& Arslan, 2014). There are many books and guidelines for the parents on how to deal with their children and how to go about raising children or coping skills. However little seems to be known about the nature of parenting style used new gerenertation on developing their children. The literature also supports that parent's attitude have significant impact on children purchase intention ( Arslan et al. 2014). The purpose of the study is to explore the new trend of parenting style in the society and its impact on the child behavior. The value of this study is to obtain the information on the different parenting styles and their impact on children behavior. This research aims to enlighten parents with information on parenting style widely used among society. Parents of particular group can benefit from the study by monitoring and effectively employing the finding of the study during developing cyclic stage of their young once. In order to explore the phenomenon of parenting and child behavior following working hypothesis are proposed

What major factors contribute in determining parenting style?

Which style is appropriate in shaping the child behavior?

\section{METHODOLOGY}

\subsection{Research Design}

The research was conducted according to the qualitative approach, which is a naturalistic approach. The research design selected to sampling, data collection technique and analysis procedures are also qualitative. The ability of qualitative data to more fully describe the phenomenon is an important consideration not only from the researcher point of view but also from the reader point of view. It provides the in depth knowledge in naturalistic environment (Ezzy, 2002). Qualitative research report typically rich with details and explore the phenomenon in depth while using the natural contextual setting. Qualitative research also provides harmony and generalizability to readers.

\subsection{Sample}

The sampling strategy in the study is purposeful sampling because in this strategy the small sample that has been systematically selected for typically relatively homogeneity provides far more confidence that the conclusion adequately represent the average members of the population than does a sample of the same size that incorporates substantial random variations (Henry, 1990) For exploring the impact of parenting style on children behavior, sample of twenty respondent are selected (14 male employee and 6 female house wife) having two or more children, in office or home setting.

\subsection{Collection of Data}

The current research haze employed in depth interview to gain the insight knowledge of the phenomenon under study. Unstructured interviews were used to gain the in-depth immersion about the effective parenting style and its effect on child behavior. The unit of analysis, which is incorporated in the current research stream, is parents having two or more children across different field level. Fourteen of the interviewees were male and only six of them are female because the limited approach is available to the housewives. Extensive literature on parenting style and its impact on children behavior was reviewed by using open-ended question from the parents. The average mean duration of the interviews was 20 to 30 minute of each. The issues of confidentiality and ethical consideration were taken in to account. A formal informed consent prior to interview has been obtained from each respondent for using of digitalized audio recording.

\subsection{Data Analysis}

The transcription process despite its being a momentous element in data analysis and central in qualitative research, was used in the study. NVIVO 10 software is used to analyze the unstructured qualitative 
data. The first step towards the data analysis is importing the data to internal source in NVIVO. The second steps are to transcribe the recorded interviews carefully and correctly. After transcription the Auto coding is run on all the recorded interviews. After making nodes does transcribing the process of coding demanded by the transcribed data. Different reports of the qualitative data generated by NVIVO software are mainly, word frequency report, tree map, tag cloud and model of the effective style of parenting are analyzed in depth to understand about the phenomena in depth.

\section{RESULTS}

In current research tributary, through homogeneous purposeful sampling of twenty parents (fourteen males; six females) from different context of society from Islamabad near village were obtained which having two or more children. Employing systematic and purposive sampling yielded data from twenty interviews ranging between 20 to 30 minutes.

The following table from N-Vivo 10 reviews the words frequency report about the unstructured recorded interviewed.

Table 1: Graphical Chart of Word Frequency Query Report.

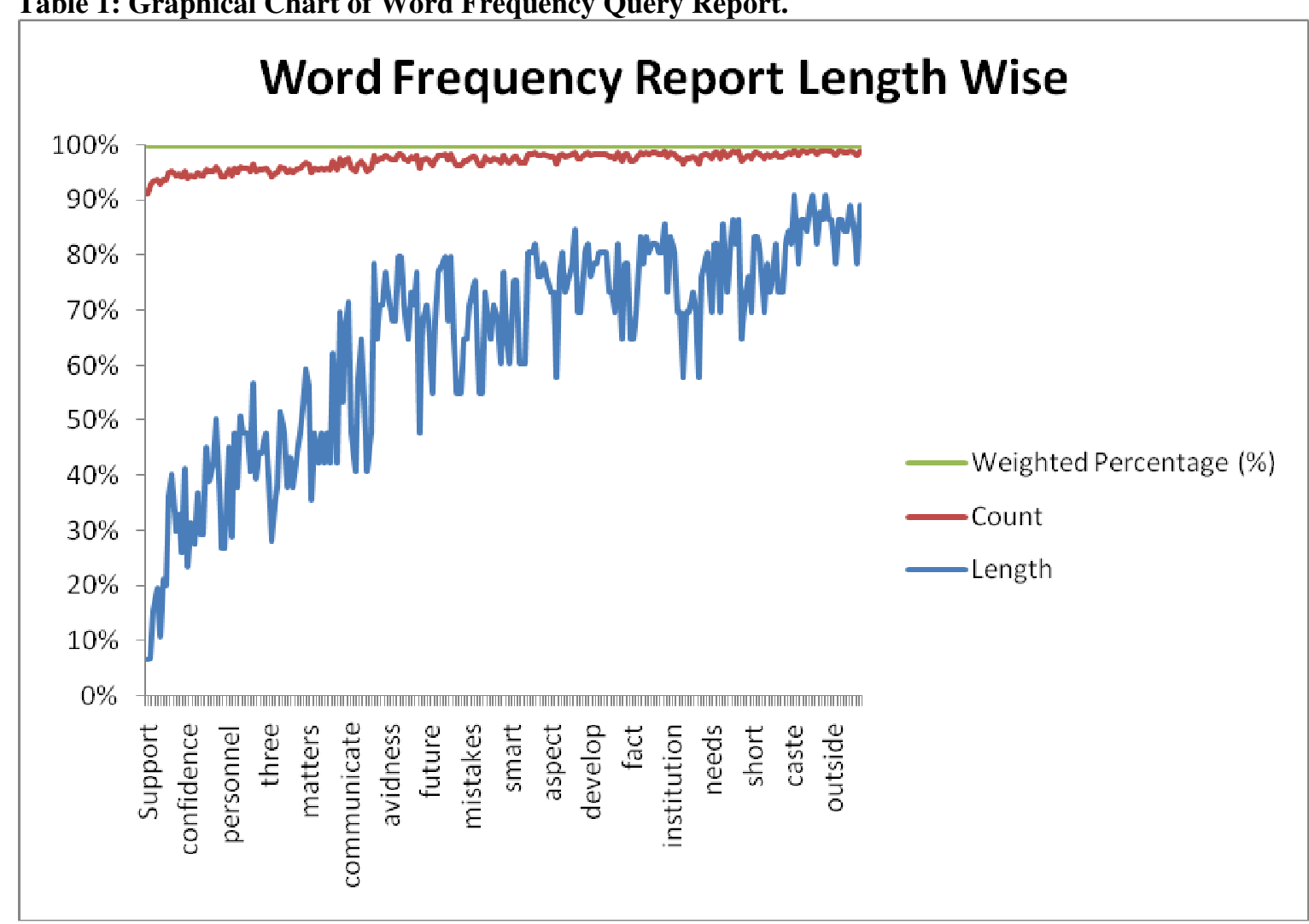

Word frequency query report the list of most frequently occurring words in the sources. It only provides the detail about the contextual content of the sources. Through the contextual content of the sources table 1 report about the major themes when farmers were discussing about the parenting style. Examination of the report shows that the 10 to $20 \%$ of the contextual content of the sources is discussion about the word "support". During the process of interviews and transcription it was noted that respondent respond that the environment in which the children are brought up have the major impact on child behavior.30 to $40 \%$ of harsh punishment word usage reveals that majority of parents are in favor of using harsh behavior and awarding punishment to their child in Pakistani context setting. In depth analysis of the transcripted data shows that the majority of parents uses it in avidness sense that harsh punishment should be avoided and it have the negative impact on child behavior. Similarly confident term covers the 30 to $35 \%$ context, transcripted data shows that communication having 50 to $60 \%$ revealing that communication is one of best source in dealing with child. In details analysis of transcripted material shows that parents consistently used word love and monitor, shows paradigm is shifting from typical extreme behavior to rather soft and patience dealing with children. Previous stated literature shows that word frequency report only the list of word repeatedly used by responded during interview. The word frequency provide the in depth analysis of the contextual material. The summary of the text query is further plotted in the 
report presented below in the form of tree map in table 3.

Table 3 Tree Map of Word Frequency Query
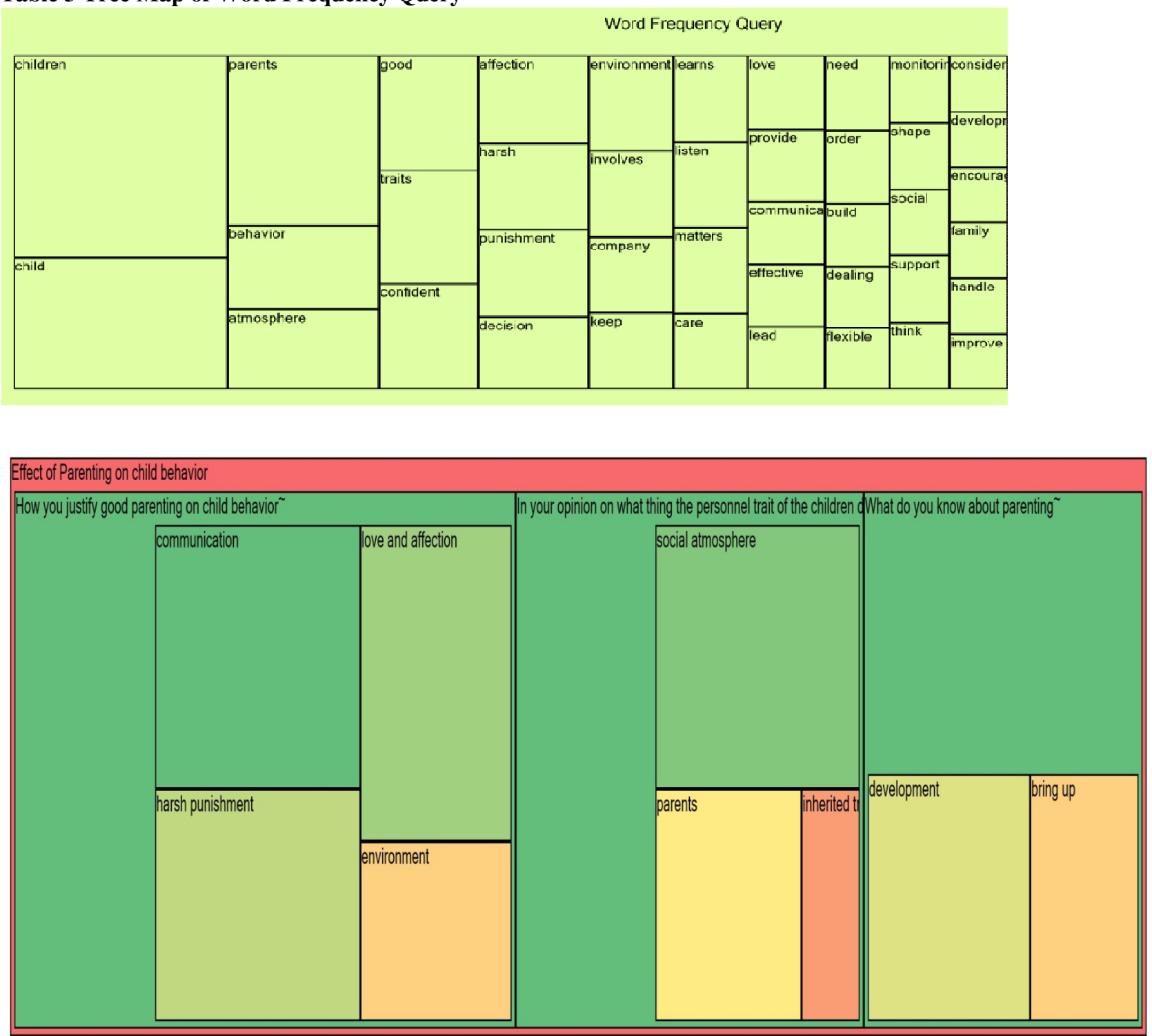

\section{Table 4 Significance of Nodes Compared by Codes}

Table 4 shows the results about the main theme generated about the good parenting practices, personal traits and knowledge of parenting among parents. When asked by good parenting practices, communication codes cover a lot of area as compared to love and affection, harsh punishment and environment. The in depth analysis of good parenting practices shows that communication between parents and children in conflict state serve the most effected tool, which have impact on good parenting practices. In second case most of the interviewee stated that social environment plays a role in shaping the personal traits of the child than parents himself followed by inherited practices. Exploring the result of third codes it is clear that majority of people are aware with the term parenting and have the sound knowledge about parenting. 
Table 5: Word Tree of the "Effective Parenting": text search query.

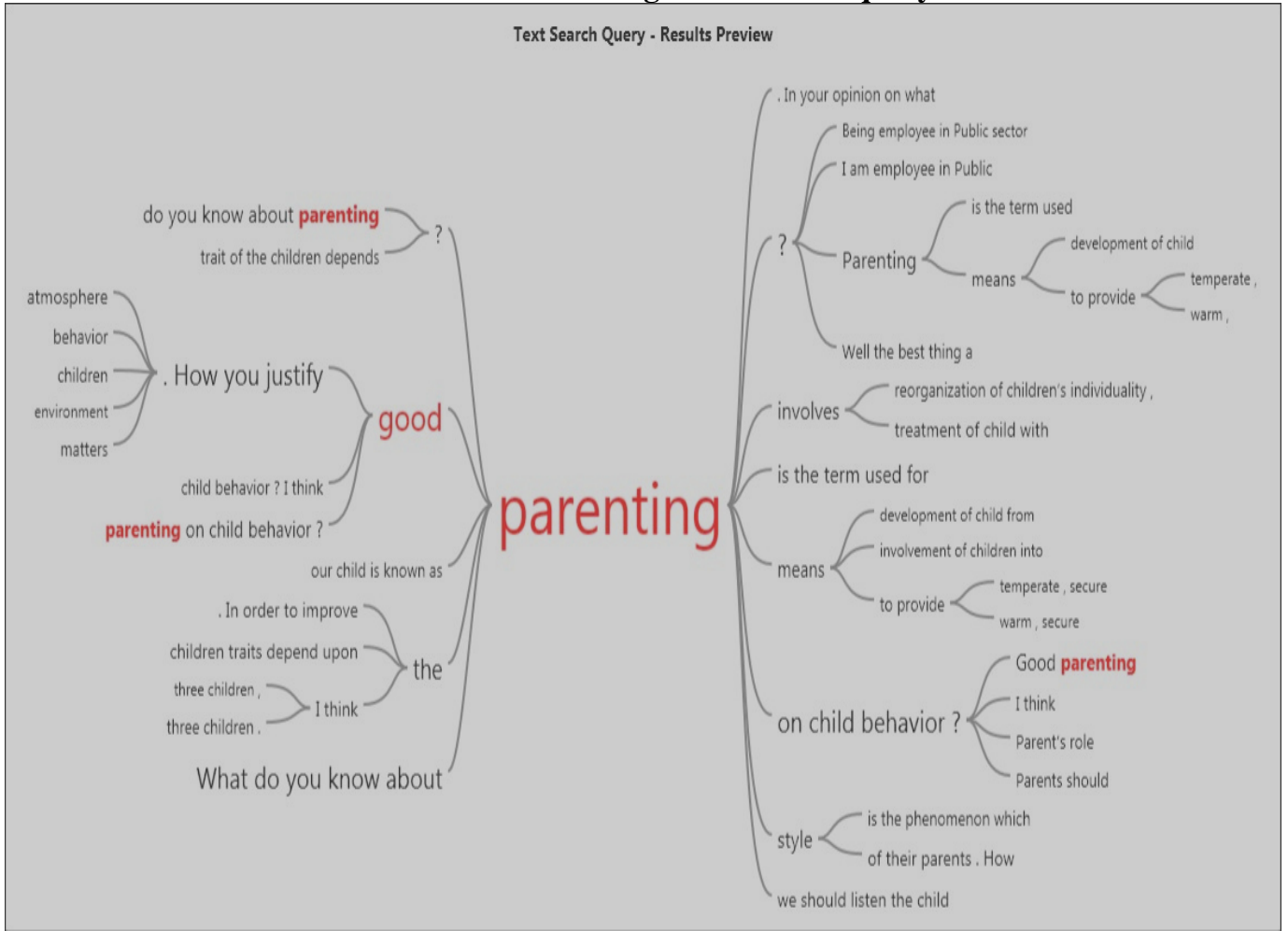

For analysis of the unstructured data the result of word tree are useful for the understanding of contextual setting of the world used in interview transcription process. To analyze the qualitative unstructured data word tree result preview are useful to comprehend the contextual setting of the word used in transcription and interview process. Word text query is an effective tool to explore the characteristic of the associated words in the logical framework. The word tree solely represent the personal perception about the parenting style and their impact on .From the table 4 which revolves around the perception of interviews we found that parenting meaning as it is associated with development and bringing up of children. Secondly we assume the good parenting, which is treatment of child with care and affection. Thirdly by analyzing in detail we found the different characteristic that has impact on child behavior such as atmosphere and environment. These two plays comprehensive role in shaping the behavior of the children.

Table 6: Model of Study

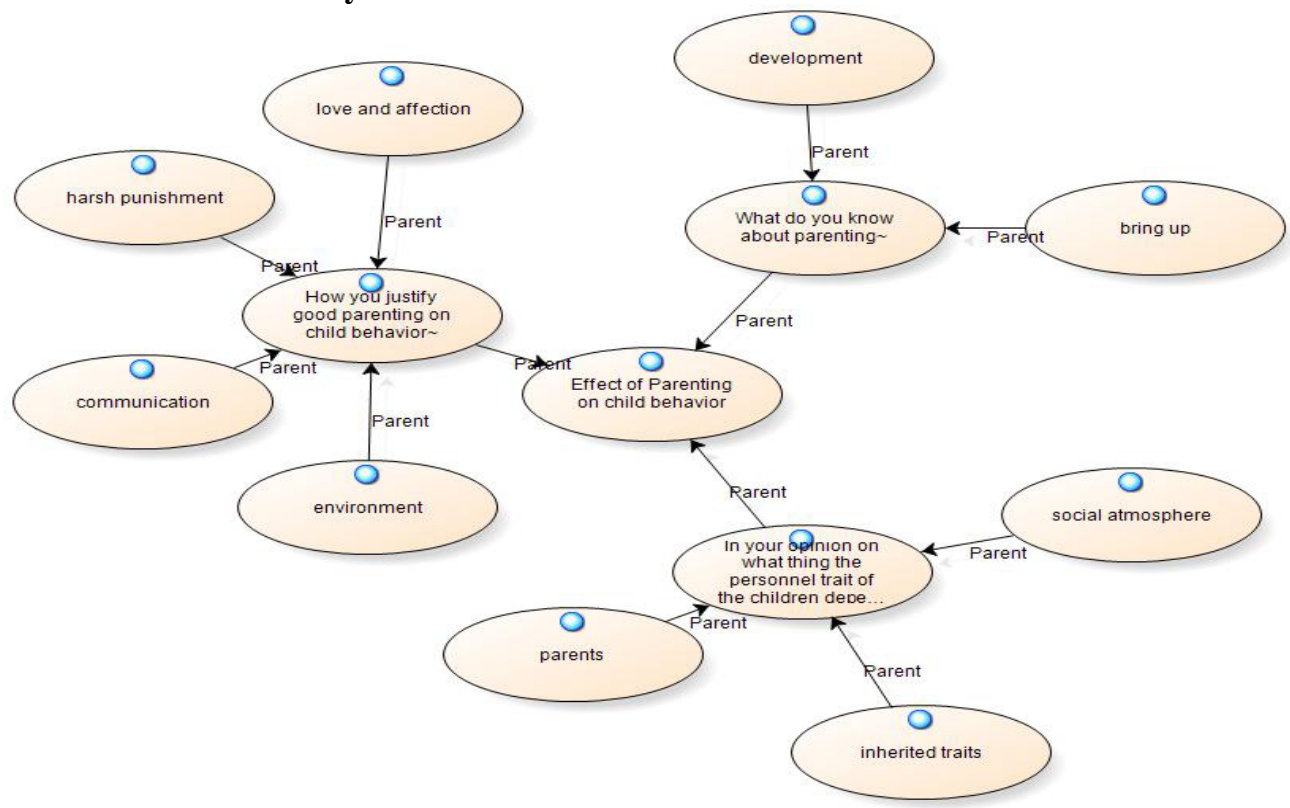


The model generated by the N-vivo 10 software after the coding of the data represented in table 6.Table 6 reports the qualitative model of the study generated by NVIVO 10 software. The objective of the study was to explore the core characteristic of parenting style having effect on child .The circular model represent the effect of different themes of parenting style on child behavior. The base of the model was codes, which were generated from nodes of the source data. Analysis of model shows that different characteristic of parenting like love, affection, environment, atmosphere and communication has a vast impact on child behavior. Good parenting is explore by effective communication,, atmosphere and affection, which social atmosphere, genetic and parents self feeling has related with traits pertaining to child behavior.

\section{DISCUSSION}

The purpose of the study is to explore the new trend of parenting style in the society and its impact on the child behavior. This research aims to enlighten parents with information on parenting style used in the society. Unstructured interviews were used to gain the in-depth immersion about the effective parenting style and its effect on child behavior. The unit of analysis, which is incorporated in the current research stream, is parents having two or more children across different field level. Eight of the interviewees were male and only two of them are female because the limited approach is available to the housewives. Different characteristic of parenting style and their impact on child behavior is effectively explored the value of this study is to obtain the information on the different parenting styles and their impact on children behavior. Parents of fastidious group will benefit from the result of the post research by receiving valuable and realistic feedback after completion of the study. The finding of the study suggests that there is definite effect of parenting style on the child behavior and parents of the studied generation prefer communication over harsh punishment, love over hate and support their children for getting effective confidence. Which are best aligned with previous studies Chen \& Kaplan, (2001) stated that parenting practices are associated with child behavior and child adjusted their behavior in the light of their styles. (Ferrari, 2002) (Mandara , 2006)(Morawska, Winter, \& Sanders, 2009). Many factors tend to persuade development temperament and ability of the children, the care they receive from their parents and concerned others, the environment on which they grow up, the opportunities provided, the support available when in need or distress and role models who represent values and goals they can identity withy. Parent plays a vitally important role in most of these aspects (Pretorrius, 2000).

\subsection{Characteristics of Good Parenting}

Effective communication is the hub of good parenting practices. Analysis of data in the study also showed that majority of good parenting is connected with effective communication. Parents support their child and preferred communication in case of conflict.The opinion drawn from the contextual analysis of data also explore that parents regards effective communication with child as a good parenting practice followed by love and affection and context on which they reside. The result about the confidence is associated with harsh punishment (Stewart, Reilly, \& Hughes, 2009). Majority of parents used the word harsh punishment with confidence in context that harsh punishment would likely be shatter child confidence. Which suggest that currently the supportive role in parenting practice was generally accepted principle among parents.

\subsection{Personal Traits of Child}

When asked about the personal trait of child most of the parents thought that social environment and their inherited behavior shape the trait of child the outcome is supported by the literature. A child development is strongly influence by the parenting style, his environment and culture in which they grow (Maggi, Irwin, Siddiqi, \& Hertzman, 2010). Therefore the relationship between parent and children is extreme important.

\section{CONCLUSION}

This study explores the new trend of parenting style in the society and its impact on the child behavior. This research aims to enlighten parents with information on parenting style used in the society. Unstructured interviews were used to gain the in-depth immersion about the effective parenting style and its effect on child behavior. The unit of analysis, which is incorporated in the current research stream, is parents having two or more children5 across different field level. Parents when asked by good parenting practices; communication covers a lot of area as compared to love and affection, harsh punishment and environment. The in depth analysis of good parenting practices shows that communication between parents and children in conflict state serve the most affected tool, which have impact on good parenting practices. In second case when asked by personal traits of child, most of the interviewee stated that social environment plays a role in shaping the personal traits of the child than parents self reflexive's followed by inherited practices. The exploration of parenting knowledge, it has cleared that majority of people were aware with the term parenting and have the sound knowledge about parenting. 


\section{References}

Arslan, M., \& Zaman, R. (2014). Unemployment and Its Determinants: A Study of Pakistan Economy (19992010). Journal of Economics and Sustainable Development, 5(13), 20-24.

Arslan, M., Umair, N., \& Zaman, R. (2014). Effect of Parental Attitude on the Relationship between Children's Exposure to Advertising and their Purchase Request. The International Journal of science commerce and humanities, 2(5).

Barbara, H. A. (2004). Styles of Parenting. The Journal of Perinatal Education, 13(1).

Bifulco, A., Moran, P. M., Ball, C., Jacobs, C., Baines, R., Bunn, A., \& Cavagin, J. (2002). Childhood adversity, parental vulnerability and disorder: examining inter-generational transmission of risk. Journal of Child Psychology and Psychiatry, 23(8), 1075-1086.

Brink , M. E. (2006). Gestalt Guidelines Assisting Parents to Enhance Psychosocial Development in Children. University of South Africa.

Chen, Z. Y., \& Kaplan, H. B. (2001). Intergenerational transmission of constructive parenting 63(1), 17-31. Journal of Marriage and Family, 63(1), 17-33.

Coleman, P. K., \& Karraker, K. H. (2000). Parenting self - efficacy among mothers of school - age children: Conceptualization, measurement, and predictors. Family Relations,, 49, 13 - 24.

Ezzy, D. (2002). Qualitative Analysis - Practice and Innovation. Routledge, London.

Ferrari, A. M. (2002, August). The impact of culture upon child rearing practices and definitions of maltreatment. Child Abuse \& Neglect, 26(8), 793-813.

Henry, G. T. (1990). Practcal Sampling (10, illustrated, reprint ed., Vol. 21). University of Michigan, USA: Sage Publications.

Hops, H., Davis, B., Leve, C., \& Sheebe, L. (2003). Cross-Generational Transmission of Aggressive Parent Behavior: A Prospective, Mediational Examination. Journal of Abnormal Child Psychology, 31(2), 161169.

Louw, A. E. (2004). Human development and family environments in global context. June 21- 23, 2004. THE INTERNATIONAL TECHNOLOGY LAW ASSOCIATION. Estonia: Global Network for Family and Community Studies,

Maggi, S., Irwin, L. J., Siddiqi, A., \& Hertzman, C. (2010). The social determinants of early child development: An overview. Journal of Paediatrics and Child Health, 46(11), 627-635,.

Mandara , J. (2006). The Impact of Family Functioning on African American Males' Academic Achievement: A Review and Clarification of the Empirical Literature. Teachers College Record, 108(2), 206-223.

Morawska, A., Winter, L., \& Sanders, M. R. (2009). Parenting knowledge and its role in the prediction of dysfunctional parenting and disruptive child behaviour. Child and Health Care Development, 35(2), 217-226.

Osborne, L. N., \& Fincham, F. D. (1996). Marital Conflict, Parent-Child Relationships, and Child Adjustment: Does Gender Matter? 42(1).

Osnat, E., \& Bonnie, B. (1995, July). Interrelatedness of marital relations and parent-child relations: A metaanalytic review. By Erel, Osnat; Burman, , Vol 118(1), Jul 1995, 108-132. Bonnie Psychological Bulletin, 118(1), pp. 108-132.

Pretorius, N. (2000). Aspects of parenting styles and the expressed fears of a selected group of pre-school children. WorldCat.

Simons, R. W., Conger, R., \& Chyi-In. (1990). Intergenerational transmission of harsh parenting. National Council on Family Relations, Seattle,.

Stewart, L., Reilly, J. J., \& Hughes, A. R. (2009). Evidence-Based Behavioral Treatment of Obesity in Children and Adolescents. Child and Adolescent Psychiatric Clinics of North America, 18(1), 189-198.

Zaman, R., \& Arslan, M. (2014). Effects of Pre-Announced Product Characteristics on Customer's Purchase Intention. European Journal of Business and Management, 6(23), 167-172. 
The IISTE is a pioneer in the Open-Access hosting service and academic event management. The aim of the firm is Accelerating Global Knowledge Sharing.

More information about the firm can be found on the homepage:

http://www.iiste.org

\section{CALL FOR JOURNAL PAPERS}

There are more than 30 peer-reviewed academic journals hosted under the hosting platform.

Prospective authors of journals can find the submission instruction on the following page: http://www.iiste.org/journals/ All the journals articles are available online to the readers all over the world without financial, legal, or technical barriers other than those inseparable from gaining access to the internet itself. Paper version of the journals is also available upon request of readers and authors.

\section{MORE RESOURCES}

Book publication information: http://www.iiste.org/book/

\section{IISTE Knowledge Sharing Partners}

EBSCO, Index Copernicus, Ulrich's Periodicals Directory, JournalTOCS, PKP Open Archives Harvester, Bielefeld Academic Search Engine, Elektronische Zeitschriftenbibliothek EZB, Open J-Gate, OCLC WorldCat, Universe Digtial Library, NewJour, Google Scholar

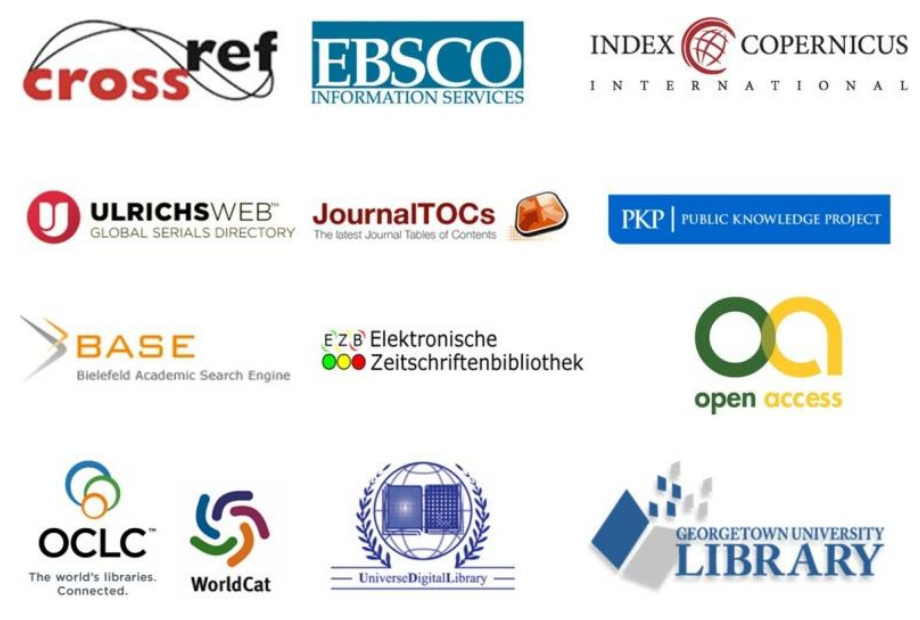

